\title{
Avaliação do paciente com artrite
}

\section{Assessment of patients with arthritis}

Sérgio C. L. de Almeida ${ }^{1,2,5}$, Luis F. Joaquim ${ }^{3,4}$, Pedro V. Schwartzmann ${ }^{1,5}$, Jarbas S Roriz-Filho ${ }^{1,6}$, Julio C. Moriguti $^{7}$

\begin{abstract}
RESUMO
Artrites são manifestações clínicas de uma série de doenças. Sua classificação etiológica é muitas vezes difícil e depende de história clínica e exame físico cuidadosos. Artrite séptica e gota se apresentam mais comumente como monoartrite aguda e quadros reacionais são geralmente poliarticulares. A internação hospitalar é fator de risco para o desenvolvimento tanto de artrites reacionais quanto para crises de gota e artrite séptica. O diagnóstico precoce é muito importante a fim de iniciar o tratamento precocemente, alívio dos sintomas e preservação da funcionalidade articular. A punção do líquido sinovial e sua análise são de fundamental importância diagnóstica nos quadros de monoartrite aguda.
\end{abstract}

Palavras-chave: Monoartrite Aguda. Gota. Artrite séptica. Artrite Reativa.

\section{Introdução}

As artrites representam um desafio diagnóstico em clínica médica e em reumatologia. O diagnóstico muitas vezes não é simples e depende da evolução que a doença toma para que se consiga boa caracterização do quadro sindrômico e construção das hipóteses diagnósticas.

A história clínica bem detalhada e exame físico, levando-se em conta forma de apresentação, evolução e padrão de acometimento articular são extremamente relevantes e não devem ser menosprezados no primeiro atendimento, nem encarados como de importância secundária aos exames complementares (que a rigor só devem ser solicitados após o diagnóstico sindrômico e as hipóteses diagnósticas serem estabelecidos).

Neste capítulo, abordaremos as monoartrites agudas, cujo manejo inicial sempre passa pelo clínico, tanto em um contexto ambulatorial como hospitalar, e alguns aspectos das poliartrites crônicas, que demandam referência rápida ao reumatologista para diagnóstico e tratamento.
1. Ex-Médico Assistente da Clínica Médica do Hospital Estadual de Ribeirão Preto.

2. Mestre em Clínica Médica pela Área de Clínica Médica da FMRPUSP.

3. Médico Assistente da Clínica Médica do Hospital Estadual de Ribeirão Preto.

4. Mestre em Fisiologia Cardiovascular pela Área de Fisiologia da FMRP-USP.

5. Pós-graduando da Área de Clínica Médica da FMRP-USP.

6. Professor Doutor da Faculdade de Medicina da Universidade de Fortaleza (CE)

7. Diretor de Atividades Clínicas do Hospital Estadual de Ribeirão Preto e Professor Livre-Docente da Divisão de Clínica Médica Geral e Geriatria da FMRP-USP.
Correspondência: Julio Cesar Morigut Hospital Estadual de Ribeirão Preto Avenida Independência, 4750. 14026-160- Ribeirão Preto - SP Telefone: 16-3602-7100 


\section{Formas de apresentação}

Deve-se levar em conta o número de articulações (mono, oligo ou poliarticular), distribuição (pequenas ou grandes articulações, envolvendo esqueleto axial ou não), tempo (aguda, subaguda ou crônica) e o padrão da evolução no caso das oligo e poliarticulares (aditiva ou migratória). O exame físico deve abranger não somente a avaliação descritiva, mas também funcional da articulação, levando-se em conta restrições na amplitude de movimento (ADM) em todos os eixos possíveis, principalmente em crianças, que muitas vezes não se queixam e as alterações a serem pesquisadas são posições e movimentações antálgicas, além de assimetria nas ADMs articulares.

\section{Monoartrites agudas}

Definem-se como agudas as artrites com até 2 semanas de duração; subagudas, de 2 a 6 e crônicas, com mais de 6 semanas.

As monoartrites agudas constituem quadros que podem representar desde urgências, como a artrite séptica, até quadros mais simples e com menor risco de dano articular, como as doenças por deposição de cristais. O padrão de acometimento, os sinais flogísticos, as patologias de base, sinais de comprometimento sistêmico e a história prévia de outras crises sempre devem ser pesquisados. Como artrite séptica é a doença a ser descartada, recomenda-se a punção articular para todo caso de monoartrite aguda (principalmente se o paciente não tem história prévia de artrite), salvo as contraindicações ao procedimento. ${ }^{1}$

\section{Contraindicações à artrocentese diagnóstica}

1. Infecção da pele e subcutâneo adjacentes ao sítio de punção;

2. Discrasias sanguíneas primárias ou secundárias ao uso de medicações ${ }^{2}$, embora não existam fortes evidências de maior número de complicações nestes pacientes.

\section{Causas de monoartrite aguda}

1. Traumática ou secundária a lesão estrutural envolvendo a articulação (ex.: ruptura meniscal ou lesão ligamentar do joelho);

2. Hemartrose: secundária às diáteses hemorrágicas como hemofilias ou uso de anticoagulantes ${ }^{2}$;

3. Secundária à deposição de microcristais: as principais são por deposição de urato monossódico (gota) e pirofosfato de cálcio (condrocalcinose);

4. Secundária a infecção.

\section{Análise do líquido sinovial:}

Uma vez que o exame de maior importância nas monoartrites agudas é a artrocentese diagnóstica, é fundamental a correta interpretação dos resultados desde o aspecto à beira do leito até a análise laboratorial (Tabela 1). Os seguintes parâmetros são importantes:

- Aspecto - o líquido deve ser claro (incolor a amarelo citrino);

- Viscosidade - com a integridade de substâncias como o ácido hialurônico, proteínas e sacarídeos complexos, o líquido sinovial normal é viscoso. À medida que o número de polimorfonucleares aumenta, aumenta também sua produção de enzimas como a hialuronidase e metaloproteinases, causando a degradação destas substâncias e a perda de sua viscosidade normal. Isto pode ser feito à beira do leito, logo que se faz a punção: o líquido inflamatório tende a pingar em gotas individuais e o não-inflamatório, por sua vez, pinga formando uma "linha";

- Teste do coágulo de mucina - reflete o grau de polimerização do ácido hialurônico pela precipitação de seu sal protéico após acidificação do líquido (realizada com a adição de ácido acético);

- Celularidade - seu padrão nos diversos tipos de líquido sinovial segue o esquema abaixo na maioria das vezes. Existe, porém, uma "zona cinzenta", onde as celularidades dos líquidos inflamatórios e sépticos se cruzam, dificultando a análise e valorizando o resultado da cultura, bem como que esta seja bem colhida e prontamente semeada para que tenha sensibilidade melhor;

- Pesquisa de microcristais - com uma gota do líquido sinovial sobre a lâmina e cobrindo com a lamínula, podemos observar os microcristais, que são identificados quanto à forma (na microscopia convencional) e quanto à birrefringência (na microscopia de luz polarizada). Cristais de urato monossódico (gota), pirofosfato de cálcio (pseudogota) e, menos comumente, hidroxiapatita ou oxalato de cálcio podem ser identificados. Os cristais de monourato de sódio aparecem em forma de agulha e têm birrefringência negativa, sendo amarelos quando paralelos ao eixo do compensador vermelho. Já os cristais de pirofosfato de cálcio são em forma de bastão ou retangulares e apresentam birrefringência positiva, ficando azuis. 


\section{Tabela 1}

Características do liquido sinovial, de acordo com o aspecto e celularidade

\begin{tabular}{llcc}
\hline Tipo & Aspecto & Número de leucócitos & $\%$ PMNs \\
\hline Normal & Claro, viscoso & $0-200$ & $<10 \%$ \\
Não-inflamatório & Claro a levemente turvo, viscoso & $200-2.000$ & $<20 \%$ \\
Inflamatório & Levemente turvo, pouco viscoso & $2.000-50.000$ & $20-70 \%$ \\
Artrite séptica & Turvo a muito turvo, com perda da viscosidade & $>50.000$ & $>70 \%$ \\
\hline
\end{tabular}

A bioquímica do líquido sinovial tem sua relevância, mas às vezes, os resultados são de difícil interpretação. Isto porque os produtos encontrados no líquido sinovial estão em equilíbrio dinâmico com o soro, guiados por pressões osmótica e hidrostática. Além disso, a falta de amostras de líquido sinovial de pessoas sadias para análise dificulta a padronização do que é patológico. Problemas ocorridos durante a coleta, como acidentes de punção, e mesmo a demora entre a coleta e a realização do exame também podem alterar os resultados. De maior importância entre os exames bioquímicos do líquido sinovial estão à glicose e o $\mathrm{pH}$ :

- Glicose - assim como no LCR e líquido pleural, se aceita como normal glicose de até $2 / 3$ da plasmática;

- $\mathrm{pH}$ - acima de 7,2;

- GRAM e cultura do líquido sinovial: para identificação de microorganismos envolvidos nos casos de artrite séptica.

\section{Artrite séptica}

Agentes infecciosos podem causar artrite. Vírus, bactérias, micobactérias, fungos e parasitas.

Dá-se o nome artrite séptica para as artrites causadas pelas bactérias e estes são quadros de morbidade e mortalidade consideráveis e o ponto fundamental deste tópico ter sempre em mente a importância de levantar a suspeita.

Costuma-se dividir a artrite séptica em gonocócica e não gonocócica, pela forma diferente de apresentação, diferentes perfis de pacientes e de agressividade do quadro3.

\section{Artrite séptica não-gonocócica}

\section{Incidência}

A incidência de artrite séptica não-gonocóccica é de 2-10/100.000 habitantes/ano em países desenvolvidos, podendo este número ser bem maior em países em desenvolvimento como o Brasil.

\section{Fatores de risco}

Artrite pré-existente (Artrite Reumatóide, gota, osteoartrite, artropatia de (harcot etc), próteses articulares, infiltrações prévias, doença autoimune concomitante, diabetes, etilismo, uso de drogas endovenosas, idade avançada, úlceras cutâneas, cirrose hepática, hemodiálise, baixo nível socioeconômico, câncer, hipogamaglobulinemia e uso de imunossupressores.

\section{Agentes mais comumente envolvidos}

1. Staphylococcus aureus - em 40 a $70 \%$ dos casos;

2. Streptococcus - em cerca de $20 \%$ dos casos (principalmente os do grupo A);

3. Bacilos Gram negativos - em cerca de $10-20 \%$ dos casos, principalmente indivíduos imunocomprometidos, em extremos de idade e nos usuários de drogas intravenosas (nos quais também é bastante comum o estáfilo). Destes, os mais comuns são a $E$. coli e o $P$. aeruginosa;

4. Salmonella sp. nos casos de hemoglobinopatia associada (sendo comum a associação com ostemomielite);

5. $10 \%$ das infecções são polimicrobianas.

\section{Vias de contaminação}

1. Hematogênica;

2. Disseminação de infecção de pele e subcutâneo adjacente;

3. Óssea em casos de osteomielite associada;

4. Iatrogênica em casos de punções articulares prévias, manipulações cirúrgicas ou artroscópicas;

5. Perda da integridade da cápsula articular como em traumas. 


\section{Quadro Clínico}

É bastante variado por conta do status imunológico do paciente e da virulência do germe. Em geral, a apresentação é como monoartrite aguda acometendo grandes articulações como joelhos, cotovelos, ombros e coxo-femorais. Sinais de comprometimento sistêmico como febre, astenia, queda do estado geral são comuns, mas não obrigatórios.

\section{Diagnóstico}

O padrão ouro é a punção com líquido purulento e os achados laboratoriais sugestivos (como no quadro acima) com o GRAM e a cultura para piogênico positivos.

1. Positividade da cultura do líquido sinovial - chega a 90\% (punções repetidas aumentam a sensibilidade e a especificidade);

2. Positividade da hemocultura - em torno de $40-50 \%$.

Há importância também para os exames de imagem:

Radiografia simples: ajuda evidenciando se há osteomielite adjacente, mas, se não houver, demora 3 a 4 semanas para começar a mostrar alguma alteração como reação periosteal e reabsorção óssea.

Ultrassonogafia: útil para quantificar o derrame articular, bem como alteração no fluxo doppler na sinóvia.

Medicina nuclear: a cintilografia com Tecnécio fica positiva em 24 a 48 horas após o início do processo, mas é inespecífica, principalmente em indivíduos com doença articular prévia; a cintilografia com Gálio ganha em especificidade, mas perde em sensibilidade.

RNM: muito útil em fase inicial, demonstrando edema de partes moles, além de sinovite, possível osteomielite e mensuração do derrame articular.

\section{Tratamento}

Existem 2 pilares de tratamento: a abordagem da cavidade articular e a antibioticoterapia. Abordagem da cavidade articular: deve-se analisar caso a caso, podendo ser feitas lavagens seriadas por via artroscópica ou abordagem aberta. Para os pacientes com contraindicações ao procedimento, pode-se tentar punções seriadas associadas à antibioticoterapia.

Como os principais germes envolvidos são o Staphylococcus aureus e o Strepococcus do grupo A, a primeira escolha de tratamento é a oxacilina e, a depender dos fatores de risco do paciente envolvido e da cultura, podemos adequar o tratamento. Alternativas são a cefazolina, clindamicina ou vancomicina. Em alguns casos, podemos associar um aminoglicosídeo ao $\beta$-lactâmico devido ao efeito sinérgico destas drogas. $^{3}$

\section{Artrite gonocócica}

\section{Quadro clínico}

O quadro articular clássico é o de poliartrite migratória, acometendo principalmente grandes articulações periféricas, descrito como "artrite bailarina", por migrar de articulação em articulação e, no final, fixarse em uma delas. Geralmente, há tenossinovite importante (principalmente em mãos, punhos, tornozelos e joelhos), associada, com edema de partes moles e dor desproporcional aos achados de exame físico.

\section{Diagnóstico}

Positividade da cultura do líquido sinovial é menor do que $25 \%$; a positividade da hemocultura bastante rara. A cultura do sangue e do líquido sinovial deve ser semeada em Agar chocolate.

A história de uretrite ou endocervicite ajudam bastante e deve-se tentar identificar o germe através de swabs de todos os pontos possíveis de envolvimento, que prontamente devem ser semeados em meio apropriado (Thayer Martin).

\section{Tratamento}

Para o tratamento da artrite gonocócica, recomenda-se ceftriaxona IM ou IV - 1,0 (g/dia) por 24 a 48 horas ou até melhora dos sintomas, seguida de ciprofloxacin - 500mg (12/12 horas) por 7 a 10 dias.

Deve-se levar em conta:

1. A alta prevalência de outras DSTs, que devem ser pesquisadas, incluindo HIV;

2. 30 - 50\% dos indivíduos com artrite gonocócica estão co-infectados com Chlamydia, que não é sensível à ceftriaxona e pode ser tratada com dose única de 1 (g) de azitromicina ou doxiciclina - $100 \mathrm{mg}-12 / 12$ horas por 7 dias em associação - lembrando que este esquema é totalmente diferente do tratamento da Chlamydia em indivíduos com artrite reativa.

3. é de fundamental importância que o parceiro seja tratado, sendo esta uma questão, às vezes, de difícil abordagem. $^{3}$ 


\section{Artrite secundária à deposição de microcristais}

Em relação às artrites secundárias a deposição de microcristais, as mais importantes são a gota e a condrocalcinose.

\section{Gota}

\section{Definição}

É a doença articular desencadeada pela deposição de cristais de monourato de sódio.

\section{Prevalência}

A prevalência é de 0,5 a $2,8 \%$ dos homens e 0,1 a $0,6 \%$ das mulheres. A distribuição entre os sexos varia de 2 a 7 homens para cada mulher afetada (dependendo das populações estudadas).

A razão para isso é a influência estrogênica na expressão de transportadores de urato nos túbulos renais, sendo que na pré-menopausa, o número deles é menor, levando a menor reabsorção tubular e maior excreção. Em geral, 2 a 3 décadas após a menopausa a prevalência de gota na mulher praticamente se iguala à masculina.

\section{Fisiopatologia}

O ácido úrico é um produto do metabolismo das bases purínicas e tem eliminação renal. São pontos importantes no metabolismo do ácido úrico:

1. Ausência da enzima uricase em humanos: Embora a espécie humana possua o gene para a uricase, enzima que metaboliza o ácido úrico, convertendo-o em alantoína (que é solúvel e facilmente excretada por via renal), esse gene não é expresso. Uma possível explicação é que o silenciamento deste gene tenha sido evolutivamente interessante para a espécie pelo fato de o ácido úrico ter propriedades antioxidantes e oferecer proteção contra os radicais livres de oxigênio. Há de se conhecer que o ácido úrico é o antioxidante mais abundante na espécie humana.

2. Produto do metabolismo das bases purínicas: portanto, doenças com alto turnover celular levam ao aumento da uricemia como neoplasias com síndrome de lise tumoral, doenças linfo e mieloproliferativas e mesmo doenças cutâneas como a psoríase.

3. Eliminação renal: é necessário haver equilíbrio entre produção e excreção de ácido úrico. Como causas da hiperuricemia, temos a hiperprodução e a hipoexcreção. Para tal diferenciação é necessária a coleta da uricosúria de 24 horas (valor normal de 250 a $750 \mathrm{mg} / \mathrm{dL}$ ), sendo que indivíduos com uricemia alta e uricosúria normal ou baixa são considerados hipoexcretores.

4. Dieta: contribui para redução da uricemia em até $1,0(\mathrm{mg} / \mathrm{dL})$. Portanto, não é aplicado para tratamento exclusivo, mas ajuda a evitar o desencadeamento de crises. O paciente deve ser orientado da dieta com ênfase principalmente na moderação do consumo do álcool.

5. Medicamentos: alguns medicamentos elevam a uricemia por aumento da produção ou pela diminuição da excreção renal do ácido úrico, sendo os principais: hidroclorotiazida, furosemida, AAS em baixa dose, pirazinamida, etambutol, ciclosporina, ácido nicotínico e o álcool.

O ácido úrico em concentrações elevadas (acima de 7,0 mg/dL no homem e $6,0 \mathrm{mg} / \mathrm{dL}$ na mulher lembrando que esses valores normais são puramente estatísticos, com base na distribuição populacional, portanto uma uricemia de $10 \mathrm{mg} / \mathrm{dL}$ no homem não é melhor do que a mesma dosagem na mulher só pelo fato de estar 1 ponto mais próximo do valor normal) passa a se depositar nos tecidos, principalmente pele, subcutâneo, articulações, parênquima renal e paredes vasculares. Por questão físico-química há constante dinâmica entre as concentrações séricas e teciduais e o indivíduo começa a ter crises de gota, uma vez que se atinja o ponto de solubilidade do líquido sinovial para o urato. Para que isto aconteça, necessita-se vários anos de deposição de ácido úrico, motivo pelo qual a gota é rara antes dos 30 anos. Além disso, devido à solubilidade do urato ser menor em temperaturas mais baixas, os primeiros locais acometidos pela gota costumam ser as articulações dos membros inferiores, principalmente, primeira metatarsofalangeana (31 C), dorso de pé (32 C), tornozelo (33 C) e joelho (35 C). Para que a gota atinja articulações de membros superiores e o urato se precipite em temperaturas mais elevadas o pool tecidual de ácido úrico tem de ser mais elevado e, geralmente, isso acontece após a primeira década de doença, já marcando nova fase, que é a gota tofácea crônica.

Uma vez precipitado o cristal de urato, este é fagocitado pelos macrófagos presentes no líquido sinovial, o que desencadeará resposta inflamatória local, levando à produção de citocinas, expressão de moléculas de adesão e migração de neutrófilos para o 
local. Uma vez que haja a migração de neutrófilos, há a liberação de metaloproteinases, produção de mais citocinas pró-inflamatórias e retroalimentação positiva da cascata, o que gera intensa atividade inflamatória.

\section{Quadro clínico}

\section{Hiperuricemia assintomática}

O indivíduo passa pelo menos 3 décadas de sua vida na fase da hiperuricemia assintomática, a não ser que tenha uma das possíveis síndromes genéticas, que levam a hiperuricemia acentuada e, nestes casos, a gota pode surgir antes dos 30 anos. Como estes defeitos metabólicos não passam de $1 \%$ dos casos de gota, apenas os citaremos neste capítulo:

1. Deficiência parcial da HPRT (hipoxantina-guanina fosforibosil transferase): síndrome de KelleySeegmiller;

2. Deficiência completa da HPRT: síndrome de LeschNyhan (retardo mental, espasticidade, coreoatetose e automutilação);

3. Hiperatividade da PRPP (fosfo-ribosil priofosfato sintetase);

4. Outras doenças que aumentem a velocidade de quebra do ATP como a deficiência de glicose 6 fosfatase (Von Gierke) e frutose-1-fosfato aldolase.

\section{Gota aguda}

Após este período surgem as primeiras crises de gota, geralmente se apresentando como monoartrites agudas com predileção pelos membros inferiores (pelos motivos já mencionados).

Especial atenção deve ser dada aos pacientes internados, que podem desenvolver crises de gota aguda poliarticular com febre, leucocitose, desvio à esquerda e elevação importante das provas inflamatórias, levando-nos aos diagnósticos diferenciais importantes com artrite séptica, celulite, endocardite, artrites reacionais a outros quadros infecciosos (piogênicos e virais) e quadro agudos de doenças granulomatosas crônicas (Síndrome de Loefgren da sarcoidose, Poncet do $M$. tuberculosis e as reações hansênicas do $M$. leprae).

Os possíveis motivos pelos quais pacientes internados tendem a desenvolver mais crises de gota são:

1. Trauma em casos cirúrgicos;

2. Jejum prolongado seguido de realimentação, tanto em pacientes que ficaram em jejum para exames ou que internaram em condições sociais precárias e passam a se alimentar de forma adequada no Hospital. Isto ocorre porque o jejum, na falta de carboidratos e lipídios ingeridos, leva ao estado catabólico, que leva a degradação acelerada de ATP, gerando ácido úrico;

3. Pela própria doença de base que motivou a internação, que pode levar o indivíduo a um estado catabólico transitório;

4. Pela redução forçada na ingestão de álcool.

Todos estes são motivos que modificam abruptamente as concentrações séricas de ácido úrico, podendo levar à precipitação articular e o desencadeamento da crise.

\section{Gota intercrítica}

Trata-se simplesmente dos anos de evolução até que o indivíduo atinja a fase de gota tofácea crônica se não tratado. As crises se tornam cada vez mais frequentes, atingindo mais articulações e podendo atingir articulações "mais quentes", como a dos membros superiores.

\section{Gota tofácea crônica}

Passa a ser uma doença crônica, podendo se manifestar com crises de mono ou poliartrite agudas frequentes ou mesmo com poliartrite crônica e simétrica acometendo pequenas e grandes articulações de membros superiores, inferiores e em alguns casos também o esqueleto axial.

São também frequentes as bursites agudas, principalmente de olécrano e pré-patelar, além de infecção secundária de alguns tofos (devido à fistulizações que podem acontecer e servem como portas de entrada).

Vale destacar que, em geral, o primeiro local onde se formam tofos é o pavilhão auricular, portanto, em casos atípicos, onde ainda não se firmou o diagnóstico etiológico da artrite, a atenção para este dado de exame físico dá uma pista importante.

\section{Diagnóstico}

O padrão ouro é a visualização dos cristais em forma de agulha com birrefringência negativa e amarelos à luz polarizada fagocitados por polimorfonucleares. Quadro clínico compatível em paciente com história prévia sugestiva bem como tofos e achados radiológicos compatíveis (erosões justa-articulares e em áreas ósseas imediatamente subjacentes aos tofos) também podem ser usados com valor preditivo eleva- 
do quando a punção for difícil (no caso, por exemplo, de podagra).

\section{Tratamento 4}

\section{Hiperuricemia assintomática}

Em relação à hiperuricemia assintomática, existe muita controvérsia na decisão de tratá-la ou não. Vêm surgindo estudos que defendem o tratamento em indivíduos com múltiplos fatores de risco cardiovasculares.

Os fatos são os seguintes:

1. Apenas $15 \%$ dos indivíduos hiperuricêmicos desenvolvem gota;

2. Este número aumenta para 30 - 50\% quando a dosagem de ácido úrico é superior a $10(\mathrm{mg} / \mathrm{dL})$ e $70 \%$ quando acima de $12(\mathrm{mg} / \mathrm{dL})$;

3. Em indivíduos com múltiplos fatores de risco cardiovascular, a hiperuricemia representa mais um fator de risco para eventos isquêmicos.

Portanto, até o momento, a postura da Sociedade Brasileira de Reumatologia recomenda considerar tratar os indivíduos com ácido úrico acima de 10 (mg/dL) e múltiplos fatores de risco cardiovasculares), além dos indivíduos com fatores predisponentes como na síndrome de lise tumoral.

\section{Tratamento da crise $^{4}$}

São 3 as opções de tratamento farmacológico: AINEs, colchicina, corticosteróides sistêmicos e intraarticulares.

A escolha de um ou de uma associação entre eles depende das condições do paciente, como idade, função renal e comorbidades como doença péptica, cardiovascular e diabetes.

Deve-se usar anti-inflamatório ou corticosteróide associado se possível à colchicina.

\section{AINEs}

Pelo fato de o processo inflamatório da gota ser intenso, costuma-se usar doses máximas de AINEs no início do tratamento, que deve durar pelo menos 7 dias. São opções:

- Indometacina: $50 \mathrm{mg}$ - 3 a 4 vezes ao dia

- Diclofenaco: $50 \mathrm{mg}$ - 8/8 horas

- Ibuprofeno: $800 \mathrm{mg}$ - 8/8 horas, reduzindo para 400 mg - $8 / 8$ horas no segundo dia

Etoricoxibe: $120 \mathrm{mg} / \mathrm{dia}$

\section{Corticosteróides}

Quando sistêmicos, recomenda-se dose de 0,5 a 1,0 (mg/kg) de prednisona ou equivalente VO por 7 dias, podendo-se reduzir gradativamente conforme o caso ou mesmo a retirada completa (sem cascata) caso o indivíduo não seja usuário crônico.

Quando intra-articulares, devem ser infundidos após aspiração da articulação envolvida e a dose depende de qual é a articulação em questão. Nossa preferência é pelo hexacetonido de triancinolona (triancil).

\section{Colchicina}

A primeira consideração em relação à colchicina é que se trata de alcalóide derivado da vinca, que pode levar a intoxicação, cuja primeira manifestação é gastrointestinal (vômitos e diarréia). Em quadros mais graves, pode haver toxicidade muscular (com fraqueza muscular predominantemente proximal, mialgia a elevação de $(\mathrm{PK})$ e neuropatias periféricas. Quadros de toxicidade medular são raros, mas foram descritos.

$\mathrm{O}$ uso concomitante de estatinas e quinolonas podem aumentar o risco destes efeitos adversos.

É uma droga de metabolismo hepático com excreção predominantemente biliar e fecal, mas $20 \%$ da droga é eliminada de forma intacta na urina, motivo pelo qual devemos nos atentar para alterações da função hepática, renal e síndromes colestáticas.

Dose: se formos usar no tratamento das crises, devemos individualizar o esquema para o paciente. São esquemas possíveis:

1. Colchicina - 0,5mg - 2/2 horas até o paciente apresentar diarréia ou resolução da dor ou atingir a dose máxima diária de $6,0 \mathrm{mg}$. Após, seguir o esquema de redução a cada $2 / 3$ dias para 6/6 horas, $8 / 8$ horas, $12 / 12$ horas e uma vez ao dia, sempre levando em conta as comorbidades do paciente em questão;

2. Colchicina - não fazer o primeiro esquema de ataque e já começar na dose de $0,5 \mathrm{mg}$ de $6 / 6$ horas, $8 /$ 8 horas, 12/12 horas e uma vez ao dia (reduções a cada $2 / 3$ dias).

\section{Tratamento hipouricemiante ${ }^{4}$}

Iniciamos a droga adequada para cada paciente, sendo um inibidor de produção para os hiperprodutores ou um uricosúrico para os hipoexcretores.

Devemos sempre levar em conta que alterações rápidas nas concentrações séricas de ácido úrico podem levar ao desencadeamento de crise, portanto: 1. Nunca devemos começar ou suspender qualquer tratamento hipouricemiante durante a crise; 
2. Quando começarmos, devemos iniciar com dose baixa e aumento gradual;

3. Devemos também lançar mão da profilaxia com colchicina ou AINE quando do início do tratamento ou nos aumentos das doses.

\section{Inibidores de produção}

Alopurinol - análogo da hipoxantina atua como inibidor da xantina-oxidase, reduzindo a produção das purinas e, por conseguinte, a produção de ácido úrico.

Deve-se iniciar com $100 \mathrm{mg} / \mathrm{dia}$ e aumentar a dose progressivamente até que se atinja níveis aceitáveis de ácido úrico. Por conta de rápidas mudanças na concentração possibilitar a precipitação dos cristais e da maior incidência de farmacodermia pelo alopurinol quando se inicia com doses maiores, devemos sempre iniciar com 100mg, podendo aumentar a dose até $600 \mathrm{mg} /$ dia.

A farmacodermia pelo alopurinol é um evento potencialmente muito grave, podendo cursar com insuficiência renal aguda por conta de nefrite intersticial, rash cutâneo febre e, ocasionalmente, reação de Stevens-Johnson ou mesmo nécrolise epidérmica tóxica (NET), com $25 \%$ de mortalidade.

Os principais fatores de risco são função renal limítrofe, uso concomitante de tiazídicos e início do alopurinol em doses maiores de $100 \mathrm{mg} /$ dia.

Febuxostat - devido ao preço e aos efeitos colaterais, fica reservado para os indivíduos que apresentaram reação de hipersensibilidade ao alopurinol. Ainda não está disponível no mercado brasileiro.

Uricosúricos - não devem ser usados se clearance de creatinina menor do que $60 \mathrm{mg} / \mathrm{dL}$, se história de cálculo renal por urato ou se o indivíduo não consegue manter uma ingestão hídrica que lhe proporcione diurese mínima de $1.500 \mathrm{~mL} / 24 \mathrm{~h}$.

Benzobromarona - deve-se iniciar com 50mg/ dia, podendo-se aumentar a dose para $100 \mathrm{mg} /$ dia.

Ainda há a possibilidade de uso da uricase, para degradação do ácido úrico em alantoína, que é um tratamento altamente efetivo, mas extremamente dispendioso, indisponível no mercado brasileiro e cercado de uma série de efeitos colaterais, além da perda de eficácia por conta da formação de anticorpos neutralizantes.

\section{Condrocalcinose}

É a doença articular causada pela deposição de cristais de pirofosfato de cálcio. A forma mais co- mum de apresentação é assintomática (como achado radiológico - até $30 \%$ dos indivíduos tem achados compatíveis na nona década de vida), mas, quando sintomática, as apresentações são diversas: crises de mono ou oligoartrite aguda (como na gota), mono ou oligoartrite crônica, poliartrite periférica simétrica (semelhante à artrite reumatóide) e mais raramente com acometimento do esqueleto axial, podendo levar à sacroileíte, calcificações discais e dos ligamentos vertebrais, incluindo dos níveis atlantoaxiais. Pelo fato de o quadro clínico poder ser tão diverso e poder nos confundir com outras doenças reumáticas, alguns autores rotulam a doença como "a grande mimetizadora".

Os sítios mais comuns de se encontrar a calcificação da cartilagem articular são os joelhos e os triângulos fibrocartilaginosos dos punhos. O padrão ouro é a análise do líquido sinovial com evidência de cristais em bastão com birrefringência positiva, mostrando-se azuis quando alinhados à luz polarizada.

A prevalência aumenta com a idade, sendo que até $30 \%$ dos adultos apresentam algum achado radiológico na nona década de vida. O tratamento da crise se faz de forma idêntica ao da gota. Para tratamento crônico, ao contrário da gota, não temos drogas que sejam capazes de diminuir a formação dos cristais, exceto em casos onde há causa subjacente como no hiperparatiroidismo, na hipomagnesemia, hipofosfatasia e hemocromatose.

Pode-se tentar o uso do carbonato de magnésio - $150 \mathrm{mg} /$ dia como tentativa de diminuir a formação do pirofosfato de cálcio, mas há pouca evidência que suporte seu uso na ausência de hipomagnesemia documentada.

\section{Considerações sobre outras artrites}

Toda artrite crônica passou por uma fase em que foi aguda. No início, o diagnóstico é mais difícil, mas o conhecimento da evolução é importante.

A maior parte das poliartrites agudas são reacionais, seja às drogas, vacinas ou infecções (virais, estreptocócicas, gonocócicas etc).

É importante para o clínico uma abordagem inicial das monoartrites agudas. É importante também, no caso das artrites crônicas, a referência o mais rápido possível para o especialista, a fim de se prevenir deformidades ou perdas funcionais.

Um grande problema se encontra nas lombalgias: trata-se de sintoma frequente $(65-90 \%$ dos adultos sofrerão um episódio de lombalgia ao longo da 
vida), perdendo apenas para os sintomas respiratórios do resfriado comum. É também a quinta causa de consulta médica. Trata-se de problema extremamente frequente e, deve-se atentar ao ritmo da dor, sendo que as inflamatórias devem ser avaliadas pelo reumatologista o quanto antes pela possibilidade de espondiloartrite (do grupo das antigas espondiloartropatias soronegativas), que se não tratadas em tempo hábil podem evoluir com grande comprometimento de todo esqueleto axial. Além disso, mesmo nas não inflamatórias, há os "sinais de alerta", que devem ser pesquisados, pois sua presença pode ser indicativa de infecção (espondilodiscites), doenças infiltrativas (neoplasias locais ou metastáticas), metabólicas (osteoporose com fratura patológica vertebral, osteomalácia, Paget e hiperparatireoidismo) e mesmo as degenerativas crônicas, que podem cursar com comprometimento neurológico (grandes osteófitos, discopatias degenerativas, hipertrofia de ligamento amarelo e espondilolistese, levando a compressão medular e síndrome do canal estreito). ${ }^{5}$

São sinais de alerta nas lombalgias: início súbito, dor noturna ou dor "em crescendo", febre, calafrios, emagrecimento, trauma, ritmo inflamatório, mas- sas abdominais, sinais de compressão medular ou radicular, irradiação bilateral da dor ou da parestesia e dor que não melhora na posição supina com as pernas fletidas sobre o tronco ou que impossibilita o paciente de encontrar posição confortável. ${ }^{5,6}$

\section{Conclusão}

A internação hospitalar está associada a morbidades, dentre elas o surgimento de artrites, principalmente séptica, reacional e gotosa.

Devemos, sempre, estar atentos às queixas dos pacientes orientados e ao exame físico daqueles que não contactuam, uma vez que podemos com o exame articular:

- Encontrar a causa da febre de origem indeterminada até então, seja ela artrite séptica ou simplesmente crise gotosa;

- Iniciar precocemente o tratamento adequado, o que muda completamente o prognóstico do paciente e da articulação envolvida

- Diagnosticar casos de artrite crônica e encaminhálos mais precocemente para o especialista, o que também muda o prognóstico.

\begin{abstract}
Arthritis are clinical manifestations of plenty of diseases. Its etiological classification is many times difficult and depends on careful clinical history and physical examination. Gout and skeptical arthritis presents commonly as acute monoarthritis and reactional arthritis are often polyarticular. Hospitalar admission is a risk factor to the development of reactional arthritis, crisis of gout and septical arthritis. Early diagnosis is imperative to start early treatment, symptom relief and articular function preservation. Synovial fluid aspiration and its analysis are of critical diagnostic importance in cases of acute monoarthritis.
\end{abstract}

Keywords: Acute Monoarthritis. Gout. Arthritis, Septic. Arthritis, Reactive.

\section{Referências Bibliográficas}

1. Chachá RCV, Louzada Jr P. Acute monoarthritis and acute polyarthritis. Medicina (Ribeirão Preto) 2003;36:418-26.

2. Thumboo J, O'Duffy JD. A Prospective study of the safety of joint and soft tissue aspirations and injections in patients taking warfarin sodium. Arthritis Rheum. 1998;41:736.

3. Hochberg MC. Septic arthritis, osteomyelitis, gonococcal and syphilitic arthritis. Rheumatology Fourth edition - Elsevier, 2008
4. Burns CM, Wotmann RL. Gout therapeutics: new drugs for an old disease. Lancet 2011; 77(9760):165-77.

5. Frymoyer JW, Cats-Baril WL. An overview of the incidences and costs of low back pain. Orthop clin North America. 1991; 22: 263-71.

6. Hart LD, Deyo RA, Cherkin DC: Physician Office visits for low back pain. Frequency, clinical evaluation and treatment patterns from a US National Survey. Spine 1995;20: 11-19. 